\title{
IMPÉRIO DO SAMBA QUEM SÃO ELES: MARCO DE RESISTÊNCIA CULTURAL NO BAIRRO DO UMARIZAL
}

\author{
Sandro Augusto Lobato de Lima ${ }^{1}$ \\ Advaldo Castro Neto ${ }^{2}$
}

RESUMO: Este artigo visa debruçar-se sobre a história dos movimentos de cultura popular do bairro do Umarizal, suas dinâmicas e suas personagens mais relevantes, tendo, como núcleo principal, o "Império do Samba Quem São Eles" - seu último marco de resistência cultural -, a fim de apontar, com base em indicadores locais, através do método de história oral, as inúmeras possibilidades que possam ter contribuído para o enfraquecimento desses movimentos, partindo do fenômeno social da gentrificação do espaço, que fragiliza os grupos economicamente mais vulneráveis, permitindo que a urbanização ocorra, sem encontrar resistência. E buscando entender a importância da agremiação carnavalesca para a manutenção da identidade cultural local, através do depoimento de seu mestre de bateria, Pedro Paulo Júnior, tem-se, então, precisa delimitação da problemática do caso, que passa, necessariamente, pelo processo de urbanização e verticalização do espaço, opinião compartilhada por outra de suas muitas personalidades notórias, o arquiteto e carnavalesco Fernando Luiz Pessoa, já que, com base em seu depoimento, pôde-se ter a real visualização do processo que culminou com a radical transformação de sua malha urbana, por meio do qual é possível inferir que tais modificações ocorreram em etapas distintas, e que foram, ao longo do tempo, enfraquecendo os movimentos de cultura popular, até culminar com sua quase total extinção.

Palavras-chave: Resistência cultural. Umarizal. Império do Samba Quem São Eles. Elitização. Reuso do espaço urbano.

\section{INTRODUÇÃO}

Localizado à zona norte da cidade de Belém, capital do estado do Pará, fazendo limites com os bairros do Reduto, ao sul; os bairros de Nazaré, Fátima e São Brás, a leste; os bairros do Telégrafo e da Pedreira, ao norte; e a Baía do Guajará a leste, o bairro do Umarizal abrange sessenta e quatro quarteirões, quatro avenidas, oito ruas e sete travessas (BRÍGIDO, 20I8), caracterizando-se por ser um bairro nobre, da Zona CentroSul de Belém, onde se encontram dois distritos administrativos de Belém, que são o

${ }^{\mathrm{I} D i s c e n t e ~ d e ~ A r q u i t e t u r a ~ e ~ U r b a n i s m o ~ d o ~ C e n t r o ~ U n i v e r s i t a ́ r i o ~ M e t r o p o l i t a n o ~ d a ~ A m a z o ̂ n i a ~-~}$ UNIFAMAZ. Integrante do projeto de iniciação científica "Memória de Belém, em suas ruas esquinas e bairros”. E-mail: sandrodestrolima@gmail.com

2 Mestrado em Artes UFPA. Docente, no Centro Universitário Metropolitano da Amazônia UNIFAMAZ. Graduado em Filosofia UFPA - 2010. 
Distrito Administrativo de Belém - DABEL e Distrito Administrativo da Sacramenta DASC (PREFEITURA DO MUNICÍPIO DE BELÉM, 202I).

Inicialmente, o bairro apresentava espaço urbano predominantemente residencial e industrial (VIEIRA et al., 2014), e era, também, local que concentrava grande número de artistas, cantores e fazedores de cultura. De modo geral, era um reduto de pessoas que se dedicavam à boemia e ao mundo das artes (CORREA, 2008). Para Penteado (1968), porém, também era um bairro habitado por população economicamente mais vulnerável, sendo o segundo mais populoso àquela época, onde se evidenciavam a carência de serviços públicos essenciais, como saneamento básico, o que impunha severas dificuldades aos seus moradores.

Essas áreas da cidade de Belém, hoje, urbanizadas, marcavam seu espaço urbano, pois estavam presentes por toda a cidade (Rodrigues, 2010). Sobre tais instalações, podemos destacar que:

Vacarias integravam a paisagem do bairro, onde capinzais serviam como alimento para o gado que fornecia leite in natura para a população. Estavam presentes na Domingos Marreiros, ocupando uma extensa área lá "na baixa", como eram conhecidos os quarteirões menos nobres da rua, em outros tempos. Aqueles, na maioria, eram submetidos a enchentes, com as chuvas abundantes, que caem na cidade. (VENISE, 200o, p. 7).

De 1870 à 1915 , dentro do período conhecido como Belle Époque - com a promoção de intensas modificações estruturais, em cidades amazônicas, reflexo do processo econômico a partir da exploração da borracha - o bairro do Umarizal estava, , afastado do centro econômico e cultural da elite burguesa, sendo local de moradia de trabalhadores informais, operários e demais camadas menos abastadas da sociedade. Ainda assim, mesmo considerando sua pouca influência, dadas as condições socioeconômicas de seus habitantes, apresentava grande diversidade cultural, no cenário da capital, visto que seus moradores desenvolveram estratégias de sociabilidade e manutenção de suas tradições, a partir de movimentos culturais, como os bumbás, também conhecidos como "Bumbameu-boi" ou "Boi-Bumbá" (QUARESMA et al., 2020).

Essas manifestações folclóricas tinham a função de atuar "como forma de crítica à situação social dos negros e índios, que combinaram elementos da comédia, do drama, da 
sátira e da tragédia - aspectos remanescentes da cultura europeia e africana -, mesclando com os costumes indígenas, que demonstram a fragilidade do homem e a força bruta de um boi” e as festas de santo (MOISÉS, RIOS, BARBOSA, 2012).

Com base na metodologia da história oral, investigou-se as manifestações culturais do bairro do Umarizal, de seu processo de ocupação territorial, como efervescente núcleo de intensas manifestações culturais e religiosas, que lhe permitiram ver surgir inúmeros grupos de bois-bumbás, cordões de pássaros, bambiás, lundus e samba, responsáveis pela construção, no transcurso de sua história, de seu tecido urbano, que lhe conferiu sua identidade.

Isso se refletia em sua forte tradição de cultura popular, que tinha, como palco, as ruas do bairro, e era muito presente no cotidiano de seus moradores, sobretudo dos negros. A partir destas manifestações, os referidos grupos desenvolveram admirável habilidade na arte da música e da dança, realizando, ao comemorar São Benedito e o Divino Espírito Santo, pomposos festejos, através das quais transmitiam sua cultura aos brincantes da época.

Um legítimo representante deste grupo, é o Mestre Martinho, que, após residir em várias outras ruas, de outros bairros, estabeleceu-se, definitivamente, à rua Bernal do Couto, no Umarizal. E, sobre ele, Salles (1980, p. I64), enfatiza que, apesar de Martinho estar com 8I anos de idade, continuava a comandar os tão famosos festejos, que duravam I5 dias, atraindo muitos participantes da cidade, porque, paralelamente a esta festa religiosa, estavam presentes danças, bailes, jogos, divertidos tipos de recreações populares, que mobilizavam os moradores do bairro. Isso, fez com que o bairro se tornasse um importante núcleo de festividades, sendo o que agregava maior adesão popular, face sua repercussão.

É a partir destas manifestações, que vamos encontrar, nas ruas do Umarizal antes da modernização que o transformou em bairro de elite, com o metro quadrado mais caro da capital paraense - as manifestações culturais, objeto desta pesquisa, que tem o Império do Samba Quem São Eles, como guardião dessa herança, havendo se tornado o 
marco-maior de todas as faces da cultura do bairro do Umarizal, de onde se irradiou a cultura negra para outros bairros periféricos, como Pedreira, Guamá, Jurunas, Cremação ou Vila da Barca.

Nos terreiros de umbanda eram onde, por exemplo, multiplicavam-se os festejos em homenagem aos orixás, que, por a seu turno, se misturavam às procissões e ladainhas, onde o tambor corria, solto, nas noites e madrugadas das rodas de batuque em que os santos mais festejados eram São Benedito, Nossa Senhora da Conceição e São Pedro, por exemplo. Ao amanhecer, as festividades se transformavam em espaços dedicados à criançada, que podiam brincar em paus-de-sebo, quebra-pote e muitas outras brincadeiras, que faziam parte de tais comemorações, e enfeitavam e ensejavam a alegria da meninada.

As festas juninas, os carnavais, com seus blocos de rua e as batalhas de confete, as pastorinhas e os presépios, marcaram o calendário sacro e profano do bairro do Umarizal (RODRIGUES, 2019).

Dos blocos carnavalescos "Unidos de Vila Farah" ao “Tá Feio" - que originou o “Império do Samba Quem São Eles” -, como movimentos culturais que orbitavam os incontáveis terreiros de umbanda do bairro, a constante presença de religiosos de matriz africana, nestes grupos, também foi importante e decisiva contribuição para o seu fortalecimento. Mas, apesar disso - e sem considerar sua importância social - as imposições da especulação imobiliária forçou o desgaste desses movimentos de cultura popular, até o fim de suas atividades, como veremos, a frente.

Se, por um lado, o bairro do Umarizal, ainda com suas características primitivas, como as vacarias, os alagados, as casas de pau-a-pique cobertas com palha, e seus terreiros de umbanda, contribuiu, significativamente, para a formação da identidade cultural de Belém, seja pela resistência à segregação, como núcleo predominantemente preto e pobre, foi, por outro, paulatinamente, através do processo de gentrificação, passando por lentas e progressivas melhorias urbanísticas, que desconstruíram suas tradições. Tais intervenções lhe trouxeram avanços significativos - sobretudo em sua malha viária e em 
sua estrutura socioterritorial -, marcados pela instalação de equipamentos urbanos ou serviços públicos, antes, inexistentes, como as melhorias na qualidade de transmissão de energia elétrica, iluminação pública, água encanada, pavimentação de vias, presença de agentes da segurança pública etc, ao passo que, também, permitiram o avanço da especulação imobiliária, transformando-o, radical e irreversivelmente, no que vemos, atualmente.

Por fim, com o aumento do custo de vida, causado pela verticalização do espaço, seus moradores foram, em sua esmagadora maioria, forçados a migrar para outras áreas da cidade, com características semelhantes, onde fosse possível manter o mesmo padrão de vida, em seus aspectos socioculturais. E essa migração, sem dúvidas, permitiu o enfraquecimento - quiçá, a extinção - do conjunto de heranças religiosas e culturais, que foram seu maior referencial, no passado, e, a partir disso, sob a bandeira do progresso a qualquer custo, é possível inferir ou apontar para uma possível causa do fenômeno observado, permitindo o entendimento da presença de fazedores e fazedoras de cultura, em vários outros bairros de Belém, como já citamos, anteriormente.

Esse fenômeno social, muitas vezes justificado pela ideia de revitalização do espaço, pode esconder outras consequências, como a da exclusão, e, para melhor entendêla, analisemos a assertiva de Sotratti (2015):

A refuncionalização de espaços urbanos degradados consiste no processo de transformação de funções de elementos arquitetônicos de um determinado processo histórico pretérito. A refuncionalização é uma consequência natural da própria reestruturação socioespacial de determinada cidade, liderada por alguns grupos sociais. Dependendo da força dos grupos sociais e de suas intencionalidades, esse processo pode abranger escalas distintas, como edifícios, bairros, cidades ou mesmo regiões.

A partir da premissa que justifica a investigação social e aponta para a imprescindível necessidade de coleta e organização de dados que contribuam para a elucidação dos fenômenos que possam ter causado o enfraquecimento desses grupos, torna-se necessária, por falta de registros históricos, a entrevista das personagens que integraram esses movimentos, a fim de lançar luz sobre um tema tão pouco estudado, 
hoje, na cidade de Belém. Neste âmbito, a história se cruza com o Império do Samba Quem São Eles, apoteótico e último reduto da cultura popular, naquela comunidade.

\section{IMPÉRIO DO SAMBA QUEM ELES: RESISTÊNCIA E TRADIÇÃO CULTURAL}

Entender a importância cultural e histórica do "Império do Samba Quem São Eles", para a salvaguarda da identidade do bairro do Umarizal, exige enfrentamento ao conceito de revitalização (ou requalificação, reabilitação, reuso etc.) que, muito além de dialogar com questões eminentemente técnicas, também pode comunicar-se com outros entendimentos, de objetivos escusos, que permeiam o sistema através do qual torna-se possível fazer uma leitura, mais aproximada, da realidade enfrentada por essa entidade da cultura popular, como último núcleo de resistência, na comunidade onde está inserida.

Tomar-se-á, como ferramenta de pesquisa, a abordagem qualitativa, com foco no contexto sociocultural dos dados coletados, uma vez que não é possível mensurá-los ou quantificá-los. Lançaremos mão, portanto, do recurso da história oral, a partir de oitivas de personagens intrinsecamente relacionadas à delimitação do problema a ser investigado.

A agremiação carnavalesca, então, pode ser considerada como um dos mais emblemáticos recortes sociais, vertiginosamente combatido pelo poder massacrante do capital, que se apropria dos espaços urbanos, à medida em que expulsa sua população originária, como resultado imediato ao fenômeno conhecido como gentrificação. Neste cenário, onde os equipamentos urbanos são pensados, planejados e erguidos, a fim de priorizar a segurança e o conforto da elite econômica, manifestações culturais de caráter popular são, não raramente, incluídas em seu planejamento estratégico, interpretados,

evidentemente, do ponto de vista dominante, que tenta ressignificá-lo, atribuindo-lhe valores de status, antes, inexistentes, que têm como objetivo manter as camadas mais vulneráveis da sociedade, afastadas. Em outras palavras, há uma substituição de narrativas culturais, que força a releitura de sua importância, neste caso, paradoxalmente 
desligada de seus atores pretéritos, que são substituídos por figuras alinhas ao gosto e consumo da elite burguesa local.

Entre as décadas de 40 e 50 do século XX - período fervilhante para o bairro do Umarizal -, onde a comunidade testemunhou grandes festividades, produzidas pela população local, que, embora vulnerável, economicamente falando, lançava mão de sua força e tradição cultural, promovendo manifestações como cordões de pássaros, boisbumbás e bailes de carnaval, fazendo surgir o que havia, de mais efervescente, para a cidade, naquele período. No entanto, a partir dos anos 5o, houve um hiato, um período de baixa produção, que coincide com um tímido, porém crescente, interesse pelo espaço urbano do lugar.

Ao chegar aos anos 7o, havendo testemunhado o fim da maioria dos núcleos culturais do bairro, o "Império do Samba Quem São Eles" assume o papel de maior mantenedor e divulgador das tradições do bairro, o que levou a escola de samba a firmarse como um importante núcleo sociocultural, atraindo uma juventude intelectual e boêmia, que, mais tarde, viria a tornar-se sua maior referência.

É neste cenário que encontramos o jovem Fernando Luiz Pessoa, um dos maiores

nomes da arquitetura e do carnaval, na capital do estado do Pará, com trabalhos reconhecidos nacionalmente, e um dos responsáveis pela renovação do modo de fazer a folia momesca, o que lhe trouxe respeito e reverência, inclusive, por um dos maiores profissionais do país, Joãozinho "Trinta”, famoso carnavalesco do Rio de Janeiro.

Em seus primeiros enredos de temáticas voltadas para a cultura regional, com toques de "paraensismos” em suas letras, o artista influenciou, direta ou indiretamente, outras agremiações coirmãs, que enveredaram pelos mesmos caminhos. Pessoa foi um dos primeiros a adotar o modelo de planta baixa, como ferramenta de planejamento dos desfiles do "Quenzão" - como a escola de samba é carinhosamente apelidada por seus amantes e admiradores -, marcando seu nome na história da entidade carnavalesca, e do próprio carnaval local e nacional, em si. 
Mas o carnavalesco estava atento ao processo de gentrificação pelo qual o bairro começaria a passar em seguida. Sobre esse processo de urbanização, Pessoa afirmou:

O processo de urbanização era inevitável. Tudo se concentrou no Umarizal, e muitas vezes, os prefeitos, naquela época, se preocuparam, muito, com o espaço da Avenida Visconde de Souza Franco, que, sendo urbanizada, passou a se constituir, de fato, como um polo muito atrativo, num espaço da cidade, que começava a crescer. Surgiram os edifícios, como consequência desse processo, e apenas o espaço de propriedade do "Império do Samba Quem São Eles", permaneceu, ainda, resistente e indiferente a toda essa especulação imobiliária. Daí, porque, ele, praticamente, é o núcleo resistente, e às vezes, perturbador da ordem e do sossego público. (PESSOA, entrevista concedida à pesquisa.)

Buscando compreender o fenômeno por trás do enfraquecimento dos movimentos culturais da cidade, no início da década de 70 - especialmente os do bairro do Umarizal -, a partir da fala de Fernando Pessoa foi possível compreender a plasticidade destas memórias, produzidas pelo método da história oral, que seguiram, a cada nova oitiva, com base em depoimentos de outras personagens, ratificando, por cruzamento de dados, as falas acerca dos mesmos fatos. Isso contribuiu, sobremodo, com a retificação de possíveis lapsos de memória, ao passo que, também, pôde elucidar detalhes, antes desprezados, por conta da incerteza ou imprecisão do relato.

Quanto a isso, segundo Pollak (1992), é a experiência do fato vivido, que carrega, em si, uma expressividade somente possível a partir do olhar de quem a viveu, podendo agregar vigorosa credibilidade e aceitabilidade, sobretudo se tratando de pesquisa cujo objeto carece de documentos históricos confiáveis.

Ao ouvirmos Maria de Lourdes Pereira da Silva, benemérita, com 48 anos de atividades, e integrante da velha guarda do "Império do Samba Quem São Eles”, é possível entender melhor um pouco da trajetória - ou histórico - da agremiação carnavalesca, antes mesmo de fixar-se em seu endereço atual. Segundo ela:

Existia uma batalha de confete, no antigo Vasco da Gama, que ficava, aqui, em frente à minha casa, na Almirante Wandenkolk, que era aquela brincadeira de salão, muito animada, onde os vizinhos se reuniam, dançavam, bebiam etc., tudo, em segurança e tranquilidade. Era uma festa e nós brincávamos à vontade. Hoje não é mais possível, por conta do trânsito e da reclamação dos moradores dos condomínios de luxo, que chegam a atirar pedras, ovos, mijo, sobre o teto da sede da escola. (SILVA, entrevista concedida à pesquisa.) 
Com o tempo, mas ainda na década de 70, o referido estabelecimento deixou de realizá-lo, sob a justificativa de que, com o asfaltamento da via e a verticalização do espaço urbano, a folia de Momo tornou-se inviável, não sendo possível garantir a segurança e a integridade físicas dos brincantes. Outro fator determinante, segundo a veterana, são as denúncias contra a escola de samba, que precisa enfrentar a presença de autoridades do poder público, como fiscalizações abusivas, sem contar os processos judiciais aos quais responde, por conta de suas atividades, no local, expondo a entidade carnavalesca a constrangimento diante de seu público.

\section{DAS VACARIAS ÀS FESTAS POPULARES: PÁLIDAS LEMBRANÇAS DO UMARIZAL}

Um riquíssimo e vasto arcabouço traduz as heranças deixadas pelos grupos de fazedores de cultura, no bairro do Umarizal. E, no desejo de tornar possível compreender sua estrutura dinâmica, em constante modificação, ouvimos o depoimento de dona Laurivalda Lopes de Souza, conhecida, carinhosamente, no bairro, como “Dona Negrita”, que nos relatou suas memórias - comprometidas, como afirmou, pela idade - mas ainda vivas, como seu amor pelo bairro e por sua agremiação carnavalesca, o Umarizal e o “Império do Samba Quem São Eles”, respectivamente.

Através de seus relatos conseguimos, inclusive, “visualizar” algumas características geográficas do lugar, que, embora não seja o objeto desta pesquisa, não foge ao seu escopo, dada sua inquestionável relevância.

Para "Dona Negrita”, a comunidade representa muito mais que apenas um núcleo de resistência da arte, sendo, antes de tudo, o bastião - ou seu último reduto - que, vivo, agoniza, padecendo sob o vertiginoso assédio do poder do capital, através da especulação imobiliária, insensível a qualquer ideia de integração ou inclusão.

"Dona Negrita" é enfática em suas palavras:

Eu vim, pra cá, com cinco anos de idade, e estou, agora, com oitenta e oito. E, aqui, na Domingos Marreiros, defronte de casa, tinha uma quadrilha, que dançava, por aí, não apenas no Umarizal. Eu não participava, apenas assistia. 
Mas se chamava 'Roceiros do Umarizal. Quando os prédios foram chegando, infelizmente, acabaram, com tudo, tudo. A gente fazia festa de São João, aqui, tinha pássaro junino, boi... era muito animado. Mas tinha muita vala, e nós tínhamos que limpar antes e, também, capinar. (SOUZA, entrevista concedida à pesquisa.)

As características rurais do bairro do Umarizal tinham, segundo seu testemunho, incontáveis capinzais, que atraíam muitos carroceiros, com seus veículos de tração animal, que iam, até o bairro, retirar capim, para alimentar seus os animais de tração.

Relatou, ainda, que, em sua casa, brincantes do "Império do Samba Quem São Eles” costumavam se reunir para criação de alegorias e confecção de fantasias, e, nessas atividades, que duravam as semanas que antecediam o carnaval, era comum que tais foliões entrassem pela noite, no labor festivo da folia momesca, como afirmou, sentenciando sua preocupação, com as novas gerações - aparentemente distantes do meio - julgando-as avessas à cultura, especialmente o samba.

Ao considerar o atual cenário de distanciamento das novas gerações, aponta, como possível causa, a elitização do bairro, que reflete, em seu entendimento, a ideia de que o carnaval seja, talvez, um conjunto de manifestações culturais características de pessoas mais pobres ou para pessoas mais idosas.

Não é possível, contudo, deixar de observar o enfraquecimento sistêmico, como viés que favoreceu o avanço do processo de verticalização, a título de melhorias urbanísticas, nem, tampouco, deixar de considerar os testemunhos dos mais antigos moradores do bairro, que vivenciaram tais transformações.

\section{A SINFONIA MOMESCA, SOB A BATUTA DO MAESTRO DA ORQUESTRA DE PERCUSSÃO}

Membro do corpo de beneméritos do "Império do Samba Quem São Eles”, onde ingressou ainda na bateria mirim, Pedro Paulo Júnior, músico e historiador, mestre de bateria da agremiação carnavalesca, também conhecido como "Maestro Pedro Paulo", emocionado, relata-nos sobre sua vivência, à frente da "Orquestra de Percussão" - epíteto 
da bateria do "Quenzão" -, e busca, na memória aguda como um si bemol, fatos relevantes, que detalha com precisão milimétrica.

Ao ingressar, compartilhava do aprendizado musical ao lado de grandes ritmistas e grandes mestres-de-bateria, como o saudoso "Mestre Carlitão", que lhe deu sua primeira oportunidade, ainda criança, atitude continuada por Luiz Guilherme, um dos maiores nomes da entidade, seu ex-presidente. E, lá, se vão trinta e quatro anos, à frente da bateria da escola de samba do Umarizal, cabendo ressaltar, ainda, a possibilidade de ser o profissional com maior tempo de atuação, em território nacional, fato que deve ser investigado pelo "Guiness World Record”, e, se confirmado, deve garantir ao brilhante “Mestre Paulo Preto", o registro no livro dos recordes, uma honraria que a nenhum outro de seus pares, jamais foi concedida.

Ao longo dos anos, porém, foi possível notar uma mudança nos movimentos culturais do bairro do Umarizal, à medida em que ocorria seu acelerado processo de urbanização, com a construção dos condomínios. Acerca disso, é mister salientar que, àquela época, antes do emprego comercial do conceito de reuso do espaço (ou requalificação) haviam subdivisões nítidas, do ponto de vista socioeconômico, que delimitava e segmentava seus moradores. Assim, na chamada "parte alta", por exemplo, concentravam-se as elites, que detinham o poder econômico, naturalmente avessas às questões da cultura popular local, enquanto, na parte baixa - onde está, ainda hoje, o "ninho da águia" - predominavam as camadas mais pobres, historicamente ligadas às manifestações culturais, sobretudo ao carnaval.

Com a mudança do espaço urbano, no entanto, notou-se uma forte elitização cultural, fomentada, sobretudo, pela abertura de shopping center, bares e similares, farmácias, clínicas oncológicas ou de estética, faculdade e os mais variados tipos de serviços, resultantes da urbanização. Também houve um incremento nos transportes públicos, já que o bairro pôde contar, a partir de então, com linhas de ônibus para todos os pontos da capital paraense. 
Embora todo o avanço urbanístico e comercial, não houve uma preocupação com as populações originárias do lugar. Quanto a essas mudanças, "Mestre Paulo Preto", afirmou:

Aquela comunidade, que tinha, antigamente, foi se afastando, seguindo suas vidas. Outros, porém faleceram ou venderam seus imóveis para construtoras, e, com isso, os prédios começaram a aparecer. Isso mudou radicalmente a cara do Umarizal. Talvez, olhando para a Doca, hoje, é possível ver algo semelhante à Avenida Paulista, mas, felizmente, o "Império do Samba Quem São Eles" ainda consegue agregar os movimentos culturais mais diversos, em torno de si. (SANTOS JÚNIOR, PP, entrevista concedida à pesquisa).

\section{MEMÓRIA: HERANÇAS CULTURAIS, LEGADOS E ÍCONES}

Os movimentos culturais, citados pelo mestre de bateria, reúnem as mais diferentes manifestações, através de ações realizadas pela escola de samba, como oficinas de percussão, corte e costura, produção de adereços carnavalescos, dança etc., que atraem e capacitam pessoas dos mais variados segmentos - o que inclui outras escolas de samba e locais da região metropolitana de Belém, como Mosqueiro, Outeiro, Icoaraci, Marituba etc, que abraçaram a semente de um trabalho árduo, persistente e solitário, desenvolvido pelo “Império do Samba Quem São Eles”.

Em face de tais articulações, o "Quenzão" resiste, no bairro do Umarizal, como sobrevivente de todos os movimentos culturais que encerraram suas atividades, restando, apenas, a tradicional e histórica escola de samba de Belém. O que significa que, do ponto de vista sociocultural, a entidade pode comemorar, afinal, além de manter-se em atividade, sempre apostou na cultura paraense como tema de seus enredos, seja falando sobre seus artistas, seus costumes ou seu folclore, seja enaltecendo seus ícones do esporte, como através do enredo para o carnaval de 2022, que irá homenagear um dos clubes mais tradicionais de Belém, a Tuna Luso Brasileira. O “Império do Samba Quem São Eles” sempre reverenciou a cultura identitária do povo do Pará, no que foi seguido por outras escolas, suas coirmãs.

Em 2020, por exemplo, seu samba levou para a Aldeia Cabana de Cultura Amazônica Davi Miguel, o legado histórico, cultural, educacional e político de um dos 
maiores estabelecimentos de educação pública de ensino médio do Brasil, e o segundo mais antigo em território nacional, o Colégio Estadual Paes de Carvalho, do qual o autor desta pesquisa foi um dos idealizadores e produtores.

Falar sobre o legado do C.E.P.C., exaltar o “Theatro da Paz", borrifar a avenida com Eneida de Moraes, Benedito Monteiro, Nilson Chaves, Estrada de Ferro de Bragança, Antônio Lemos, Cobra Norato, Lendas Amazônicas, Chuva ou Largo de Nazaré, são, na prática, características indissociáveis de sua própria história. E a escola mantém, com seus nomes mais notáveis, como o próprio entrevistado, Pedro Paulo Júnior, além de Neder Charone, Luiz Guilherme, Davi Miguel, Fernando "Gogó de Ouro”, Nazaré Paes de Carvalho, Gláucio Sapucahy, Eduardo Vieira, Alcyr Guimarães, Simão Jatene, Margarida Malar, Edgar Augusto e tantos outros, uma relação de reverência e respeito., num misto de gratidão e culto à tais personalidades.

Por conta disso, talvez, durante as décadas de 70 e final de 8o, a agremiação carnavalesca tenha sido a coqueluche da folia, capaz de atrair a nata dos mais famosos artistas locais, que se reuniam na sede da entidade, quando, ao sair do Bar do Parque, findavam a noite, até o raiar do sol, nas rodas da escola samba, á época, chamado de "Castelão do Samba".

Ao longo de sua história, a escola, antevendo tempos difíceis para a cultura, por conta da verticalização do espaço urbano, em torno de si, preocupou-se em não apenas atrair intelectuais para sua sede, como formá-los. Este aspecto formador, aglutinador de intelectuais, reforçou sua importância no bairro, e contribuiu, significativamente, para que houvesse um trabalho voltado para as novas gerações (as internas, herdeiras dos que já fazem parte da agremiação) e a capacitação técnica de novos talentos.

Desta iniciativa, surgiram novos bailarinos, novos músicos, novos letristas e compositores, como o grupo "Meninos do Umarizal”, que já colecionam obras importantíssimas, com sambas-enredo campeões, não apenas de sua própria escola de samba, como de outras. São nomes que solidificam a entidade, reforçam sua história, 
ratificam sua importância, e pulverizam o mais altivo e legítimo representante da cultura popular, no bairro do Umarizal, onde resiste, bravamente.

\section{DO IGARAPÉ DAS ALMAS AO CARNAVAL, A COROA DO PROCESSO DE RESSIGNIFICAÇÃO ESPACIAL E A CONSEQUENTE EXCLUSÃO DOS MAIS POBRES}

Como uma das mais importantes avenidas da capital paraense, a Visconde de Souza Franco, popularmente chamada de "Doca" - que também serve de limite entre os bairros do Umarizal e do Reduto - tem, em todo o seu processo de urbanização, um papel fundamental, sobretudo no tocante ao conceito de elitização espacial e todas as suas consequências, amplamente citadas nesta pesquisa.

As profundas transformações pelas quais passou, seus significados e relações de uso, são fruto das intervenções executadas pelo poder público - em raros casos, da iniciativa privada - são norteadores para um melhor entendimento do significado de tais mudanças. A respeito dessas modificações, Rodrigues (2013) ressalta que:

Modificou profundamente seu desenho urbano nas últimas três décadas,
alterando, em pouco tempo, sua planta original, fazendo emergir um bairro de
serviços, no tradicional bairro de moradia, onde novas relações de sociabilidades
se estabelecem. A modernidade inaugura um novo tempo onde o passado
pertence aos mais velhos, cuja fragmentação do tempo traz a sensação de não
pertencimento à sociedade do individualismo e dos guetos, que teima em inserir
o habitante na rede de relações sociais inscritas no novo ambiente, em oposição
à teia de sociabilidades, tradicionalmente construída, como resultado do
convívio com as pessoas e seu habitat, ao longo dos tempos.

Seguindo sua linha de pesquisa, é possível determinar, além das mudanças geográficas, drásticas alterações do estrato social do bairro do Umarizal, que lhe impôs uma nova dinâmica sociocultural, interferindo decisivamente na utilização de seu espaço urbano, o que inclui todos os usos, comumente associados.

Sobre esse fenômeno, o jornalista Edgar Augusto Proença, em entrevista à pesquisa, pontuou, como um dos principais fatores que desencadearam o enfraquecimento dos espaços de cultura, as melhorias urbanísticas realizadas na via, no início da década de 9o, durante da gestão do então prefeito Hélio Gueiros. 
Após uma discreta melhoria em sua infraestrutura básica, ainda na administração do Coronel Nélio Lobato, Gueiros implementou as mais significativas mudanças no lugar, incluindo asfaltamento e, além disso, passou a fazer muita publicidade do logradouro, ao se declarar "tarado por Doca", o que engendrou o início da vida noturna, que, por sua vez, ao atrair cada vez mais pessoas dispostas a gastar, também inflacionou o preço do metro quadrado, tornando o custo de vida mais caro para seus moradores.

Seguiu-se, então, sua transformação absoluta, de tímida e acanhada via, para o palco das principais manifestações culturais da cidade, o que incluía carnavais fora de época, e o próprio desfile de carnaval das escolas de samba de Belém. A partir daquele ponto, já não era possível impedir o processo de tomada do espaço público pela elite econômica, encantada com as melhorias e a glamourização da avenida que, logo, estaria tomada de lojas de toda sorte, sem contar bares e similares.

Nesse período, nota-se uma forte expansão das construtoras instaladas na capital, e, como reflexo, ainda segundo Proença, viu-se o completo desaparecimento de algumas vilas que costumavam agregar as costureiras do "Império do Samba Quem São Eles”, que atravessavam noites, confeccionando fantasias, voluntariamente, para a agremiação carnavalesca. Segundo Proença:

\footnotetext{
Enquanto a Doca se tornou um ponto atrativo, as laterais (transversais) da Doca, começaram a crescer, também. Então, aquele bairro, que era pobre, pouco a pouco, começou a se urbanizar. E mais: aquilo que eu falava, das costureiras, das vielas, começou a sumir, porque as vielas começaram a ser derrubadas, para a construção de prédios. Só do lado da minha casa, tinha uma viela, linda, que o pessoal do Quem São Eles frequentava essa vila, sobretudo que a gente fechava, aqui, a Domingos Marreiros, um pedaço dela, pra fazer festa do Quem São Eles. (PROENÇA, entrevista concedida à pesquisa).
}

Muitas mudanças ocorreram, já na esteira das primeiras melhorias, sendo visíveis, se considerarmos, por exemplo, o surgimento de bares, boites, e, até, mesmo, igrejas, como a Paróquia da São José, como consequente das transformações experimentadas pela comunidade local. A Almirante Wandenkolk, inclusive, onde está a agremiação carnavalesca, de rua lamacenta, sem movimentações e tráfego de veículos, mudou para uma avenida apinhada de boutiques, sem jamais ter sido planejada para funcionar como 
área comercial. "Nós víamos, com pena, as casas mais pobres sendo derrubadas, e, no lugar delas, vinha a construção de algum condomínio”, relembra o jornalista.

Saudoso, relatou à pesquisa um trecho de um breve diálogo que manteve com o poeta Ruy Barata, em sua residência, localizada no início da via, onde mora há décadas:

O Ruy, que morava na Generalíssimo [Avenida Generalíssimo Deodoro] vinha pra minha casa para assistir o restante do carnaval. E uma vez, quando dormiu aqui em casa, num dos desfiles do carnaval, pela manhã, quando acordei encontrei o poeta na sacada do prédio olhando pra rua. Eu me aproximei pra falar com ele e, ele disse: "Olha, Edgar, o Umarizal. O meu bairro do Umarizal! Este bairro não existe mais.” Isto foi há 20 anos atrás, ou até mais. E ele dizia: "Olha, Edgar, estes edifícios que estão fazendo aqui no Umarizal.”. Aí eu virei pra ele e disse: "Ruy, a gente não pode fazer nada. É o progresso que chega. Tu achas que o Umarizal ia ficar, eternamente, como igapó? Não ia ficar.” Ao que ele replicou: "É, Edgar... eu fico muito triste." Eu dei de ombros. Virei, porque eu achei que era um pouco de saudosismo. Hoje, quase quarenta anos depois, eu olho pelo retrovisor e vejo prédios para todos os lados, e concluo que o Ruy tinha razão”. (Edgar Augusto Proença em entrevista à pesquisa)

\section{TÁ FEIO! MAS QUEM SÃO ELES?}

Originalmente, o "Império do Samba Quem São Eles” foi um bloco de carnaval que surgiu a partir de dissidências com a extinta escola de samba "Boêmios da Campina", do bairro homônimo. Logo, é possível deduzir que, em sua origem, o "Quenzão" não estava inserido na comunidade do bairro do Umarizal, o que só veio ocorrer, anos, mais tarde, devido a persistência de seus beneméritos.

Em sua história, repleta de curiosidades, é possível destacar um fato que aconteceu num dos arrastões do bloco, e está relacionado à origem de seu próprio nome. Talvez devido à falta de recursos, ou, mesmo, por se tratar de um grupo de incipientes ébrios do carnaval, segundo relatos dos mais antigos, tem-se notícias de que, em uma de suas primeiras apresentações públicas, ainda como bloco dissidente, seu desfile não chamava a atenção do público, devido às condições precárias das fantasias, ao que, em determinado momento, alguém passou, olhou e disse:

_ Ah, Tá feio!

Como a irreverência e o carnaval parecem indissociáveis, o bloco passou a se apresentar com o nome de “Tá Feio”, resultando numa brincadeira, que deu certo, a dura 
até os dias de hoje. Somente dois anos, depois, é que seus fundadores decidiram mudar o nome do bloco para "Quem São Eles?”, com interrogação, inicialmente, ainda no bairro da Campina, onde funcionava uma sede improvisada, situada na rua o7 de Setembro, num prédio que existe, ainda hoje, como fiel depositário - ou testemunha - da história do mais notável núcleo de resistência cultural do bairro do Umarizal.

De lá, a agremiação carnavalesca mudou-se para a Travessa Padre Eutíquio, às proximidades de onde, atualmente, está o shopping Pátio Belém, tendo funcionado, a partir de então, nos fundos de uma lavanderia, a "Paraense". Somente daí é que a escola de samba passou a funcionar na Avenida Almirante Wandenkolk, na casa de um de seus brincantes, conhecido como Téo, que cedeu a própria residência para que a entidade continuasse suas atividades.

Foi somente no início dos anos 70 que surgiu a oportunidade de alugar um terreno na mesma via e, com a realização de rodas de samba, promoções, sorteios e bingos envolvendo a comunidade que, àquela altura, já tinha noção de pertencimento em relação ao grupo - além de deixar de desfilar por um ano, a fim de economizar recursos financeiros, a escola de samba conseguiu, finalmente, comprar o referido lote, com dinheiro emprestado pelo médico Cláudio Lobato. É onde está, até hoje, mesmo pressionada, sob constantes acusações de poluição sonora, e por incomodar a elite econômica local, que não aceita o "barulho" emitido de sua sede, por ocasião de suas atividades, no carnaval ou fora dele.

\section{UMARIZAL É O MEU LUGAR}

Conclui-se, a partir desta pesquisa, que, embora haja uma força sistêmica, fruto da especulação imobiliária, responsável pelo enfraquecimento dos movimentos de cultura popular, no bairro do Umarizal, não encontramos, durante a pesquisa, quaisquer outros dados que apontassem para outro caminho, que não fosse o da elitização da malha urbana, que, por obvio, tende a expulsar os mais pobres, ressignificando seus espaços, elevando o custo de vida, e impedindo sua permanência, no local. 
Através do processo de gentrificação, tais transformações, rigorosamente travestidas de progresso, com seus inegáveis melhoramentos, colocaram em curso, no bairro do Umarizal, um lento, progressivo e eficaz modelo de exclusão, que passa, obrigatoriamente, pelo enfraquecimento das manifestações populares, quem tem, no "Império do Samba Quem São Eles" seu último marco de resistência. E foi possível evidenciar, através da abordagem qualitativa, o contexto sociocultural dos atores envolvidos, através de seus depoimentos.

As entrevistas, as leituras dos autores adotados como referências bibliográficas, confrontados com a realidade dos fatos testemunhados por aqueles que os relataram, tendo, como base, o método da história oral, apontam para um mecanismo aparentemente estruturado, com vistas a derrubar, financeiramente, a entidade carnavalesca, através de ações judiciais que questionam suas atividades culturais, em nome de um pressuposto sossego, que busca respaldo nas leis ambientais.

O “Império do Samba Quem São Eles”, a partir da década de 70, viveu seu ápice histórico, onde a elite que, hoje, o repele, concorria para seus badalados eventos sociais, mas que, com a série de melhorias executadas na Avenida Visconde de Souza Franco, somadas à especulação imobiliária, viu a necessidade de divorciar-se da agremiação carnavalesca. A partir do início da década de 9o, portanto, a entidade iniciou uma luta constante, por sua própria existência, uma vez que, aqueles que, antes, se aglomeravam, em sua sede, hoje, tentam silenciar-lhe.

E não basta, para o massacrante poder do capital, o reconhecimento de utilidade pública, como entidade fomentadora, que zela pela salvaguarda da cultura paraense, já que, nesse processo de gentrificação, há uma engenharia sistêmica excludente, que visa tão somente o fim de suas atividades, em nome do lucro, a todo custo.

Assim que, ao constatar as mudanças radicais, pelas quais o bairro passou, também é possível notar, ao longo desse processo, que não houve qualquer preocupação 
com ações de inclusão e salvaguarda de suas tradições. Via-se, na medida em que os condomínios eram construídos, o fim dos terreiros de umbanda, que, por sua vez, deixavam de abrigar outras manifestações, como quadrilhas, cordões de pássaros etc, num efeito dominó, planejado e implantando, com esse objetivo.

Deste quadro, restou, apenas, o “Império do Samba Quem São Eles”, que persiste, sob fogo cruzado, em manter suas atividades, atento às pressões a que está submetido. E a resistência pode estar nas novas gerações, cabendo, ao "Quenzão", como marco da cultura popular, lançar mão de recursos que dialoguem com a juventude, através da ocupação de seu espaço, para que se torne um catalizador de outras manifestações populares, também dentro do bairro, o que pode agregar este público, ainda que reconheçamos a hercúlea tarefa de alcançar esse objetivo, sem apoio do Estado.

Enfim, é como afirma seu samba exaltação:

$$
\begin{aligned}
& \text { O meu samba tem orgulho de morar aqui } \\
& \text { Esse é meu chão, Umarizal é meu lugar } \\
& \text { Convido todos pra sambar e aplaudir } \\
& \text { Escola do povo nosso show vai começar... }
\end{aligned}
$$

\section{REFERÊNCIAS}

BRÍGIDO, R. A. Crescimento horizontal do bairro Umarizal - Belém. Disponível em: 〈https://pt.slideshare.net/Drigobri/crescimento-horizontal-do-bairro-umarizal-belm>. Acessado em I4 de novembro de 2021;

Distritos Administrativos de Belém. Disponível em $:<h t t p: / / w w w . b e l e m \cdot p a . g o v \cdot b r / a p p / c 2 m s / v / ? \mathrm{id}=\mathrm{I} 8 \&$ conteudo=4762 $>$ Acessado em I4 de novembro de 2021, às 14 h4om;

\section{ENTREVISTAS}

MOISÉS, J. de O., RIOS, M. M. \& BARBOSA, R. R. A manifestação bumba-meu-boi no município de Caxias - MA atualmente, 2012;

PENTEADO, Antonio Rocha. Belém. Estudo de Geografia Urbana. Universidade Federal do Pará, 1968;

PESSOA, Fernando Luiz de Souza. Entrevista concedida a Sandro Lima, sobre os movimentos culturais do bairro do Umarizal. Belém - PA, 25/09/2021. 
POLLAK, Michael. Memória e identidade social. Estudos históricos, Rio de Janeiro, v. 5, I992. Disponível

em:

〈http://www.pgedf.ufpr.br/memoria\%20e\%2oidentidadesocial\%20A\%20capraro\%202.pdf $>$ Acessado em o8 de agosto de 2021, às Ioho3m;

PROENÇA, Edgar Augusto. Entrevista concedida a Sandro Lima, sobre os movimentos culturais do bairro do Umarizal. Belém - PA, 27/04/2021;

QUARESMA et al. "As Sonoras": Lazer e Sociabilidade na Perifireria de Belém-PA [Brasil]. I960 - I970, Rosa dos Ventos, vol. I2, 2020 - Universidade de Caxias do Sul;

RODRIGUES, Venize Nazaré Ramos. Bairro e Memória: Umarizal das vacarias aos espigões. (Belém, 1950/2000). In: XXVI SIMPÓSIO NACIONAL DE HISTÓRIA. 2013. Natal - RN, 2013;

SALLES, Vicente. O Negro no Pará sob o regime da escravidão., 3 ed., Belém: IAP; Programa Raizes, 2005;

SANTOS JÚNIOR, Pedro Paulo. Entrevista concedida a Sandro Lima, sobre os movimentos culturais do bairro do Umarizal. Belém - PA, 25/09/2021;

SILVA, Maria de Lourdes Ferreira da. Entrevista concedida a Sandro Lima, sobre os movimentos culturais do bairro do Umarizal. Belém - PA, 09/o9/202I;

SOTRATTI, Marcelo Antônio. Dicionário do Patrimônio Cultural. Instituto do Patrimônio Histórico e Artístico Nacional - IPHAN, 2021. Disponível em: 〈http://portal.iphan.gov.br/dicionarioPatrimonioCultural/detalhes/58/revitalizacao > Acessado em 23 de julho de 2021, às 22hi7m;

SOUZA, Laurivalda Lopes. Entrevista concedida a Sandro Lima, sobre os movimentos culturais do bairro do Umarizal. Belém - PA, 2I/o9/202I;

THOMPSON, Paul. A voz do passado: história oral. Rio de Janeiro, Paz e Terra, I992; 